\title{
Malnutrition and high childhood mortality among the Onge tribe of the Andaman and Nicobar Islands
}

\author{
VG Rao*†, AP Sugunan, MV Murhekar and SC Sehgal \\ Regional Medical Research Centre (Indian Council of Medical Research), Post Bag No. 13, Port Blair 744 101, \\ Andaman and Nicobar Islands
}

Submitted 8 September 2004: Accepted 12 May 2005

\begin{abstract}
Objectives: A study was conducted among the Onge tribe of the Andaman and Nicobar Islands with the objectives of identifying demographic factors responsible for the decline in their population and assessing their nutritional status, which is an important determinant of child survival.

Study design and subjects: The study included estimation of indices of fertility and child mortality, and assessment of nutritional status. All individuals of the Onge community settled on Little Andaman Island were included.

Results: The mean total marital fertility rate was estimated to be 5.15 live births per woman and the general fertility rate was 200 live births per 1000 married-womanyears. Although the gross reproduction rate was estimated to be 2.2 female children per married woman, the net reproduction rate was only 0.9 surviving female child per married woman. The mean infant mortality rate during the past 30 years was 192.7 per 1000 live births, and the child survival rate was found to be only $53.2 \%$. A mild to moderate degree of malnutrition was found in $85 \%$ of children of pre-school age and severe malnutrition in 10\%. The Onges had low intakes of iron, vitamin A and vitamin C. All the screened Onges were found to be infested with one or more intestinal parasites.

Conclusions: High childhood mortality appears to be the predominant demographic factor responsible for the decline in the Onge population. The high prevalence of undernutrition and micronutrient deficiency disorders could be important factors contributing to the high childhood mortality.
\end{abstract}

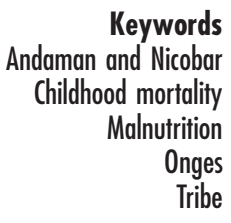

The Onge tribe is one of the four Negreto races of the Andaman and Nicobar Islands. Until the late 1960s the Onges were the sole inhabitants of Little Andaman Island, and a century ago they were $672^{1}$ in number. Although the Onges were hostile to outsiders initially, friendly contact was established with them as early as $1885^{1}$. Little Andaman was opened to migrants from other islands and mainland India in 1967, and in the early 1970s Onges were rehabilitated in two settlement areas - one at Dugong Creek and the other at South Bay of the island. The Onge population has been declining steadily during the past century and their number at the latest census (1991) was $99^{2}$. This steady decline in the population over the last 100 years has led to a situation where survival of the tribe itself has become doubtful.

Other than population enumeration data published at 10-year intervals by the Director of Census operations, no other authentic data on their demographic characteristics or vital indices are available, and the reasons behind the steady decline in their population have not been studied in †Present address: Regional Medical Research Council for Tribals, Nagpur Road, PO Garha, Jabalpur 482 003, Madhya Pradesh, India. detail. It is also not clear whether this decline is due to low fertility rates, high mortality rates or both. The Onges are in a phase of transition from their primitive ways of life to a more modern, civilised lifestyle. Consequently, every aspect of their life, including economic activities, living and working environment and dietary habits, has been subject to drastic changes. In the absence of authentic information on demographic parameters and the changes in such parameters over the years, the impact of these changes cannot be assessed. Earlier studies carried out among Onges had shown that their intakes of protein and many micronutrients decreased between 1964 and $1989^{3}$. More recent studies carried out among Great Andamanese - another Negreto tribe of Andamans facing a similar problem of continuous decline in population - have revealed high child mortality rates and high prevalences of malnutrition and micronutrient deficiency disorders among children (VG Rao et al., unpublished work). Malnutrition is a factor known to be closely associated with child mortality rates ${ }^{4,5}$, and it has been shown that a considerable proportion of childhood deaths can be attributed to malnutrition. Since there are many things in 
common between Great Andamanese and Onges, including the nature of problems they face, it was considered important to study child survival and related aspects among the Onges. To this end, the present study was conducted among the Onges with the objectives of identifying demographic factors responsible for the decline in their population and assessing their nutritional status, in terms of both dietary composition and prevalence of nutritional deficiency disorders, which is an important determinant of child survival.

\section{Material and methods}

The study was carried out in May-June 1997 and had the following components: a demographic survey, a diet survey, anthropometry, clinical examination and determination of laboratory parameters.

\section{Demograpby}

The population of Onges settled at Dugong Creek and South Bay was enumerated and their ages and sex noted. All the ever-married women in the community were interviewed for their fertility performance and mortality among their children. A trained Dai and a social worker, who had long years of acquaintance with the Onges, helped in interviewing the ladies. The data collected included: (1) number of years of reproductively active marital life to date; (2) total number of conceptions; (3) number of live births and sex of babies; and (4) deaths of children and the age at death. The distribution of the population in various age and sex groups was compared with the population structure of India, and the statistical significance of the difference was tested using the MantelHaenszel summary chi-square test. The sex ratio was also compared with the all-India sex ratio.

General fertility rate $^{6}$ was calculated for all the evermarried women present in the community. Total marital fertility rate ${ }^{6}$ was calculated from the fertility data obtained from ever-married women who had completed their families. Gross reproduction rate and net reproduction rate $^{6}$ were calculated for those women who had completed their families and for all ever-married women separately. Infant and under-five mortality rates ${ }^{7}$ were calculated from the data on childhood deaths obtained from all the women.

\section{Diet survey}

The diet survey was carried out in all families and involved weighing raw food before the preparation of each meal on three consecutive days. Food weights were obtained using a kitchen balance whose accuracy was ascertained by comparing its readings against those of an electronic balance (Sartorius Electronic Balance model LP 2200 S) at various weights. Leftover food was weighed and the quantity was adjusted for the next day when it is consumed. Food from outside the house consumed by any of the family members was also taken into account. Consumption units in each family were calculated by taking into account age, sex, physiological status and occupation of each family member. Average food consumption per consumption unit (CU) was calculated for each family and for the whole community. Average nutrient consumption was computed using data on nutritive values of Indian foods published by the National Institute of Nutrition, Hyderabad ${ }^{8}$. These values were compared with the recommended dietary allowances?.

\section{Nutritional antbropometry}

Length of children aged 2 years or less was measured using an infantometer and the height of older children was measured using an anthropometer rod, following standard techniques ${ }^{10}$. Weight was measured using a weighing machine (Atco Digital Personal Scale model MS-1), which was calibrated using standard weights. The ages of all the children were obtained from the birth records available with the social worker. The height and weight of each child was compared with the National Center for Health Statistics $^{11}$ reference data for the child's age and sex. Children under 6 years of age were classified into different nutritional grades following the classification of Gomez et al. ${ }^{12}$. Children below 19 years of age were classified into different grades of nutritional status as per Waterlow's classification $^{13}$. Body mass index (BMI) ${ }^{10}$ was calculated for all adults and they were classified into different grades of chronic energy deficiency using the cut-off values suggested by the World Health Organization (WHO) ${ }^{10}$.

\section{Clinical examination}

All individuals were examined by a medical epidemiologist for clinical symptoms and signs such as angular stomatitis, conjunctival xerosis, night blindness, Bitot's spots, phrynoderma, conjunctival pallor and thyroid enlargement. Attempts were also made to study vaccination coverage. However, it was difficult to obtain this information reliably from the mothers as their literacy levels were rather poor. In addition, the auxiliary nurse midwife who used to maintain the vaccination records was away on leave during the period of the survey and hence these records could not be obtained.

\section{Laboratory studies}

Haemoglobin concentration was measured using the cyanmethaemoglobin method $^{14}$. The grade of nutritional anaemia of each person was ascertained by considering the cut-off values of haemoglobin concentration for the age, sex and physiological status of that person ${ }^{15}$. Stool samples were collected from all community members and examined under a microscope using direct saline mount and iodine preparations to determine if ova and cysts of intestinal parasites were present. 


\section{Results}

\section{Population}

The present population of Onges settled in Dugong Creek and South Bay together consists of 105 persons. The age and sex distribution of the present population is shown in Table 1. Although the population structure is different from that of India, the level of statistical significance for this difference was low $\left(\chi^{2}=26.467, \mathrm{df}=13\right.$, $P=0.0147)$. Children aged 14 years or less constituted $32.4 \%$ of the total population, those in the age group 1544 years $43.8 \%$ and those aged 45 years and above $23.3 \%$. The oldest Onge man was 67 years old and the oldest woman 65 years. The overall sex ratio of the population was 842.1 females for 1000 males, which is not statistically different from the sex ratio of $933 / 1000$ for India $\left(\chi^{2}=0.2749, P=0.60\right)$. Women in the reproductive age group of 15-44 years constituted $19 \%$ of the total population as against the national (Indian) average of $22 \%$.

\section{Fertility indices}

Twenty-seven out of 30 ever-married women were interviewed for fertility performance and childhood mortality. Thirteen of these 27 women had completed their families either because of attaining menopause or because they were widowed. These 13 women had 67 live births during their reproductive period, giving an average of 5.15 live births per woman. This represents the mean total marital fertility rate among them for the past 30 years. To date, these 27 women together have had 544 years of reproductively active marital life and they have given birth to 109 live babies, giving 200 live births for 1000 marriedwoman-years in the reproductive age group, which represents the mean general fertility rate among them during the past 30 years.

The 27 ever-married women in the community had given birth to 60 female babies, giving a gross reproduction rate of 2.2 female children per married woman. Since

Table 1 Age and sex distribution of Onges

\begin{tabular}{|c|c|c|c|c|c|c|}
\hline \multirow{2}{*}{$\begin{array}{l}\text { Age group } \\
\text { (years) }\end{array}$} & \multicolumn{2}{|c|}{ Females } & \multicolumn{2}{|c|}{ Males } & \multicolumn{2}{|c|}{ Total } \\
\hline & $n$ & $\%$ & $n$ & $\%$ & $n$ & $\%$ \\
\hline $0-4$ & 8 & 16.67 & 9 & 15.79 & 17 & 16.19 \\
\hline $5-9$ & 5 & 10.42 & 3 & 5.26 & 8 & 7.62 \\
\hline $10-14$ & 4 & 8.33 & 5 & 8.77 & 9 & 8.57 \\
\hline $15-19$ & 5 & 10.42 & 5 & 8.77 & 10 & 9.52 \\
\hline $20-24$ & 3 & 6.25 & 3 & 5.26 & 6 & 5.71 \\
\hline $25-29$ & 3 & 6.25 & 4 & 7.02 & 7 & 6.67 \\
\hline $30-34$ & 2 & 4.17 & 3 & 5.26 & 5 & 4.76 \\
\hline $35-39$ & 4 & 8.33 & 8 & 14.04 & 12 & 11.43 \\
\hline $40-44$ & 3 & 6.25 & 3 & 5.26 & 6 & 5.71 \\
\hline $45-49$ & 4 & 8.33 & 5 & 8.77 & 9 & 8.57 \\
\hline $50-54$ & 4 & 8.33 & 5 & 8.77 & 9 & 8.57 \\
\hline $55-59$ & 2 & 4.17 & 2 & 3.51 & 4 & 3.81 \\
\hline $60-64$ & 1 & 2.08 & 1 & 1.75 & 2 & 1.90 \\
\hline $65-69$ & 0 & 0.00 & 1 & 1.75 & 1 & 0.95 \\
\hline $70+$ & 0 & 0.00 & 0 & 0.00 & 0 & 0.00 \\
\hline Total & 48 & 100.00 & 57 & 100.00 & 105 & 100.00 \\
\hline
\end{tabular}

many of the women are yet to complete their families, this figure for all women will be an underestimate. If only those women who have completed their families are considered, the gross reproduction rate is 3.0 female children per married woman (39 female births/13 women). The net reproduction rate, which is a better indicator of population growth, is 0.9 if all of the women are considered and 0.92 if only those women who have completed their families are considered.

\section{Infant and childbood mortality}

Twenty-one of the 109 babies born alive to the 27 evermarried women died before their first year of life, giving a mean infant mortality rate of 192.7 per 1000 live births during the past 30 years. Another 30 children died before attaining 5 years of age and 12 died after the age of 5 years, giving a total of 63 deaths. Only 58 of the 109 live-born babies survived up to the age of 5 years, giving an underfive mortality rate of 468 per 1000 live births and a child

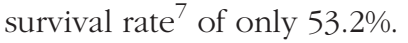

\section{Housing, sanitation and water supply}

Onges live in wooden houses with tin roofs built by the Andaman and Nicobar Administration that have a living room, a veranda and a kitchen. Common sanitary latrines are constructed in the settlement but nobody uses these for defecation. All practise open field defecation away from the houses, in the jungle, but children often defecate near the houses. The settlement at Dugong Creek has four sanitary wells and all of the families use water from two of these four wells for their drinking and cooking needs. The South Bay settlement has two sanitary wells. Water supply was found to be adequate and available near the households. Water is stored in plastic cans and used for drinking as well as other purposes.

\section{Dietary habits}

Table 2 shows the profile of food-group consumption per CU. The intakes of green leafy vegetables, other vegetables, fruits, milk and milk products were much less than the respective recommended dietary allowances $^{9}$. Their average daily consumption of fats and pulses was nearly four times the recommended dietary allowance and the consumption of fish was almost double the recommended allowance. Although the average consumption of many of the food groups per CU in the community was above the recommended level, the consumption pattern differed from family to family. Of the families, $7 \%$ to $100 \%$ had deficient intakes of various food groups except pulses, fats and oils. The intakes of all food groups except cereals, pulses and fats were deficient in the majority of the families.

Average intake of various nutrients per CU is given in Table 3. Average consumption per CU of all nutrients, except iron, vitamin $\mathrm{A}$ and vitamin $\mathrm{C}$, was above the recommended levels. Almost all of the families had 
Table 2 Intake of different food groups by Onges

\begin{tabular}{lccrr}
\hline Food group & RDA $(\mathrm{g})$ & Families consuming less than RDA (\%) & Average intake $(\mathrm{g})$ & \% deficit/excess \\
\hline Cereals and millets & 460 & 6.67 & 558.20 & +21.34 \\
Pulses & 40 & 0.00 & 153.49 & +283.72 \\
Green leafy vegetables & 50 & 93.33 & 8.58 & -82.84 \\
Other vegetables & 60 & 100.00 & 30.00 & -100.00 \\
Roots and tubers & 50 & 73.33 & 79.21 & -39.42 \\
Fats and oils & 20 & 0.00 & 4.27 & +296.05 \\
Fruits & 30 & 96.67 & 58.75 & -85.77 \\
Fish & 30 & 73.33 & 21.91 & +95.83 \\
Meat and poultry & 30 & 80.00 & 26.72 & -26.97 \\
Milk and milk products & 150 & 100.00 & 30.96 & -82.19 \\
Sugar & 30 & - & 0.16 & +3.20 \\
Condiments and spices & - & 0 & 304.40 & - \\
Nuts and oil seeds & - & 0 & & - \\
\hline
\end{tabular}

RDA - Recommended Dietary Allowance.

deficient intakes of vitamin A and vitamin C, whereas 63\% of families had deficient iron intake and $37 \%$ of families had deficient riboflavin intake. No family had deficient intakes of protein and fat. Their average daily fat consumption was more than 10 times the recommended daily allowance and their intakes of protein, energy and calcium almost double the recommended allowances.

\section{Nutritional anthropometry}

Seventeen out of 20 (85\%) children, aged 6 years or less, had a mild to moderate degree of malnutrition and another two (10\%) had severe malnutrition, making the prevalence of under-nourishment among pre-school children 95\% (Table 4). There were 41 children in the age group of $0-18$ years and 38 (92.7\%) among them were malnourished, with 37 showing both stunting and wasting and one showing only wasting. This high prevalence of both stunting and wasting among children indicates that the problem of malnutrition in the community has existed for quite a long time. Malnutrition was found to be equally prevalent among boys and girls. Onge adults (aged 20 years and above) had an average BMI of 21.0 (standard deviation 3.2) $\mathrm{kg} \mathrm{m}^{-2}$, with 11 (20\%) showing chronic energy deficiency and five (9\%) presenting obesity. The prevalence of chronic energy deficiency in females was more than double that in males (12.9\% vs. 29.2\%). Distribution of the Onge adults according to their BMI is given in Table 5 .

\section{Nutritional deficiency signs}

Clinical signs of anaemia were present in 35 out of 96 (36.5\%) individuals. The anaemia prevalence was found to be more or less equal in adults of both sexes, whereas girls showed a higher prevalence of anaemia than boys ( $45.5 \%$ vs. 19.0\%). Bitot's spots were observed in three children and conjunctival xerosis in another five. Other nutritional deficiency signs observed were angular stomatitis in 18 persons (18.8\%) and goitre in nine (9.4\%).

\section{Haemoglobin levels}

Haemoglobin estimation was done in 67 Onges. Fifty-eight out of 67 persons (86.6\%) were found to be anaemic according to the WHO definition of anaemia ${ }^{15}$. Moderate and severe anaemia was found to be more common among women and children, whereas most anaemic men had only a mild degree of anaemia. The observed high prevalence of anaemia corroborates the deficient dietary intake of iron by Onges as revealed in the diet survey.

\section{Parasitic infections}

Stool samples were collected and examined for ova and cysts of intestinal parasites. All of the 40 persons examined

Table 3 Intake of various nutrients by Onges

\begin{tabular}{|c|c|c|c|c|}
\hline Nutrient & RDA & $\begin{array}{l}\text { Families } \\
\text { consuming } \\
\text { less than } \\
\text { RDA (\%) }\end{array}$ & $\begin{array}{c}\text { Average } \\
\text { intake } \\
\left(\mathrm{CUday}^{-1}\right)\end{array}$ & $\begin{array}{c}\% \text { deficit/ } \\
\text { excess }\end{array}$ \\
\hline Protein (g) & 60 & 0.00 & 124.43 & +107.38 \\
\hline Fat $(\mathrm{g})$ & 20 & 0.00 & 215.25 & +976.25 \\
\hline Energy (kcal) & 2425 & 0.00 & 4864.01 & +100.57 \\
\hline Calcium (mg) & 400 & 6.67 & 780.68 & +95.17 \\
\hline Iron (mg) & 28 & 63.33 & 26.37 & -5.83 \\
\hline Vitamin A $(\mu \mathrm{g})$ & 600 & 96.67 & 293.09 & -51.16 \\
\hline Thiamine (mg) & 1.2 & 0.00 & 2.14 & +78.33 \\
\hline Riboflavin (mg) & 1.4 & 36.67 & 1.68 & +20.00 \\
\hline Niacin (mg) & 16 & 0.00 & 23.23 & +45.18 \\
\hline Vitamin C (mg) & 40 & 100.00 & 7.08 & -82.30 \\
\hline
\end{tabular}

RDA - Recommended Dietary Allowance; CU - consumption unit.

Table 4 Prevalence of malnutrition among Onge children of pre-school age (Gomez classification)

\begin{tabular}{lccccc}
\hline & & \multicolumn{4}{c}{ Grade of malnutrition } \\
\cline { 3 - 6 } Sex & No. covered & Mild & Moderate & Severe & Total \\
\hline Male & 10 & $1(10.0)^{*}$ & $7(70.0)$ & $1(10.0)$ & $9(90.0)$ \\
Female & 10 & $2(20.0)$ & $7(70.0)$ & $1(10.0)$ & $10(100.0)$ \\
Total & 20 & $3(15.0)$ & $14(70.0)$ & $2(10.0)$ & $19(95.0)$ \\
\hline
\end{tabular}

${ }^{*}$ Figures in parentheses indicate percentages. 
Table 5 Mean body mass index (BMI) of Onge adults compared with rural Indians

\begin{tabular}{|c|c|c|c|c|}
\hline \multirow[b]{2}{*}{ Sex } & \multirow{2}{*}{$\begin{array}{l}\text { Age group } \\
\text { (years) }\end{array}$} & \multicolumn{2}{|c|}{$\begin{array}{l}\text { Mean BMI } \\
\left(\mathrm{kg} \mathrm{m}^{-2}\right)\end{array}$} & \multirow{2}{*}{$\begin{array}{c}\text { Rural India } \\
\text { (NNMB 1991/92) }\end{array}$} \\
\hline & & 1989 & 1997 & \\
\hline \multirow[t]{4}{*}{ Male } & $20-29$ & 22 & 21.8 & 19.24 \\
\hline & $30-39$ & 21 & 21.3 & 19.56 \\
\hline & $40-49$ & 20 & 18.5 & 19.88 \\
\hline & $\geq 50$ & 19 & 17.0 & 19.48 \\
\hline \multirow[t]{4}{*}{ Female } & $20-29$ & 22 & 21.6 & 19.3 \\
\hline & $30-39$ & 23 & 20.1 & 19.6 \\
\hline & $40-49$ & 23 & 21.3 & 19.6 \\
\hline & $\geq 50$ & 20 & 21.8 & 19.8 \\
\hline
\end{tabular}

NNMB - National Nutrition Monitoring Board.

were found to harbour one or more types of intestinal parasites. The commonest parasite encountered was Ascaris lumbricoides (90\%) followed by Trichuris trichura (37.5\%). Mixed infection with A. lumbricoides and T. trichura was present in $27.5 \%$. No other parasitic infestations were present in any of the examined Onges.

\section{Discussion}

The present population of Onges is 105. Although this represents a marginal increase compared with their population in 1991, one cannot conclude that the negative trend in their population growth has really reversed. Despite the drastic reduction in population size over the last century, the structure of their present population has more or less maintained its balance. In the case of some other tribes, like the Shompens of Great Nicobar, such drastic decline in population was accompanied by structural imbalances ${ }^{16}$. The male/female composition and the relative proportions of children, young adults and older persons are not significantly different from such parameters of the Indian population.

The total marital fertility rate of 5.15 live births per woman, the general fertility rate of 200 live births per 1000 married woman and the gross reproduction rate of 3.0 female children per married woman are all quite satisfactory and consistent with a positive population growth. In this situation there is little reason to suspect reduced fertility as the cause behind the continuous decline in their population.

Compared with this satisfactory level of fertility, the mortality rates among infants and under-fives are very high. The average infant mortality rate and under-five mortality rate of 33 countries with the highest rates are 130 and 211 per 1000 live births, respectively ${ }^{17}$. In comparison, the infant mortality rate among Onges (193 per 1000 live births) is 50\% higher and the under-five mortality rate (468 per 1000 live births) more than double. The mean infant mortality rate among the Onges during the past 30 years is higher than the highest recorded rate of 150 per 1000 live births among the rural population of India during the same period $^{18,19}$. More than half of all live-born babies die before they reach adulthood. Vaccine-preventable infectious diseases could be important causes of high childhood mortality and hence information about vaccination coverage would have been important in understanding the role of these diseases. However, due to logistical problems, this information could not be obtained. Although the gross reproduction rate is 3.0 female children per married woman, because of the high mortality rates among female children the net reproduction rate becomes 0.9 , indicating that sufficient numbers of girls are not reaching adulthood to replace the mothers. The fertility and mortality figures indicate that the reason behind the continuous decline in the Onge population is the high rates of mortality among infants and children.

The prevalence of mild to moderate malnutrition among Onge children was $85 \%$ and that of severe malnutrition was $10 \%$. This is in contrast to the total absence of protein-energy malnutrition among them in $1971^{20}$. The observed reduction in the intakes of protein and micronutrients between 1964 and $1989^{3}$ would be expected to have had a negative impact on the nutritional status of Onge children.

Although the cause of the high rate of childhood mortality among Onges is not known, the results of assessment of nutritional status among children indicate that malnutrition must be playing a significant role in this. Analysis of pooled data obtained from several studies shows that children with mild to moderate degrees of malnutrition have a relative risk of 2.2 for death under 5 years of age, and children with severe malnutrition have a relative risk of $6.8^{21}$. The prevalence of severe malnutrition was very low among the Onge children and malnutrition as such cannot be the direct cause of reduced child survival among them. But milder degrees of malnutrition were found to be highly prevalent, and the risk of death below 5 years of age in children with such degrees of malnutrition is more than double that of well-nourished children. Hence, mild to moderate malnutrition must be playing a hidden role in reducing child survival, although the immediate causes of childhood deaths could be infectious diseases like diarrhoea, acute respiratory infection, etc. To understand the exact reasons behind the high child mortality, detailed prospective studies on cause-specific mortality and morbidity are required.

The diet survey showed more than sufficient intakes of energy, protein and fat by all families. The nutritional status of adults also corroborates this finding. But some imbalances in diet composition were observed. The Onge diet was deficient in micronutrients like iron, vitamin A and vitamin C. These deficiencies are reflected in the high prevalence of anaemia observed among them. Clinical signs of other micronutrient deficiency disorders, like angular stomatitis, conjunctival xerosis and Bitot's spots, were also observed. These micronutrient deficiencies 
might also have played an important role in the observed high mortality rates among children.

The Onge families have sufficient availability of food as revealed by the diet survey. Hence the factors responsible for the observed high prevalence rates of malnutrition among Onge children must be either faulty weaning and child-rearing practices or a high incidence of infections and infestations. Intestinal parasitic infestation, which is a contributory factor for malnutrition, was found to be prevalent in almost $100 \%$ of the population. In addition to being a predisposing factor for malnutrition, intestinal parasitic infestation is considered a general indicator of the local level of development, because wherever living conditions are poor, a high prevalence of soil-transmitted helminthic infections is encountered ${ }^{22}$. In the case of Onges, it is not poverty in the strict sense that is responsible for this, as they have no scarcity of resources. The Andaman and Nicobar Administration provides them with all the necessary amenities. Probably it is a lack of awareness and poor hygienic practices that is responsible for this high prevalence of infestations. In spite of having sanitary latrines in their settlement, almost all of them prefer to defecate in the open. Although there are sanitary wells in their settlement, built by the Andaman and Nicobar Administration, storage and handling of drinking water in all families was found to be unhygienic. With all of these adverse factors of poor environmental sanitation, unhygienic personal habits and high prevalence of micronutrient deficiency disorders, the community appears to be at a high risk for infections and infestations. The children in such a community become the victims of a vicious cycle of malnutrition-infection-malnutrition.

Extremely high mortality rates among the Onge children have led to a situation where survival of the tribe itself has become doubtful. The role of malnutrition in childhood mortality is often unapparent. Although the role of factors like genetic disorders and other morbidities as the cause of high childhood mortality rates is not known as no data are available, malnutrition appears to be a contributory factor. As the causes of malnutrition among Onges could be either faulty weaning practices or frequent episodes of infections, programmes to improve the situation should address these issues. The community needs to be educated about healthy child-rearing practices, environmental and personal hygiene, and better utilisation of available food resources. The rationing system also requires some modifications so that the low intakes of micronutrients such as iron and vitamins $\mathrm{A}$ and $\mathrm{C}$ are rectified. The Onge community is an ideal population for periodic mass deworming, as the number of persons in the community is limited and the prevalence of intestinal parasitoses is extremely high. A comprehensive child survival programme with supplementary feeding, nutritional prophylaxis, growth and development monitoring, immunisation and prompt medical attention during illnesses needs to be devised and implemented with active participation of the community.

\section{Acknowledgements}

The authors gratefully acknowledge the help and cooperation given by the Department of Tribal Welfare, Andaman and Nicobar Administration and Andaman Adim Jan Jati Vikas Samiti. The authors are also thankful to the fieldworkers, Shri RC Rao and Shri SR Ghosal, and laboratory technician, Shri Mohd Rafi, for their assistance.

\section{References}

1 Basu BK. The Onge: Negrito Hunter-Gatherers of Little Andaman. Calcutta: Seagull Books, 1990.

2 Directorate of Census Operations, Andaman and Nicobar Islands. Census of India 1991 - Series 27: Andaman and Nicobar Islands - Final Population Totals. Port Blair: Directorate of Census Operations, 1993.

3 Hanumantha Rao D, Brahmam GNV, Pralhad Rao N. Primitive Tribal Groups of Andaman and Nicobar Islands - Health and Nutrition Survey. Hyderabad: National Institute of Nutrition, Indian Council of Medical Research, 1989.

4 Pelletier DL, Frongillo EA Jr, Schroeder DG, Habicht JP. The effects of malnutrition on child mortality in developing countries. Bulletin of the World Health Organization 1995; 73(4): 443-8.

5 Scrimshaw NS, Taylor CE, Gorden JE. Interaction of Nutrition and Infection. World Health Organization (WHO) Monograph Series No. 57. Geneva: WHO, 1968.

6 Park K. Demography and family planning. In: Park K, ed. Park's Textbook of Preventive and Social Medicine, 14th ed. Jabalpur: Banarsi Das Bhanot: 1995; 282-312.

7 Park K. Preventive medicine in obstetrics, paediatrics and geriatrics. In: Park K, ed. Park's Textbook of Preventive and Social Medicine, 14th ed. Jabalpur: Banarsi Das Bhanot, 1995; 313-44.

8 Gopalan C, Rama Sastri BV, Balasubramanian SC (revised and updated by Narasinga Rao BS, Deosthale YG, Pant KC). Nutritive Value of Indian Foods. Hyderabad: National Institute of Nutrition, Indian Council of Medical Research, 1996.

9 Indian Council of Medical Research (ICMR). Nutrient Requirements and Recommended Dietary Allowances for Indians: A Report of the Expert Group of the Indian Council of Medical Research. New Delhi: ICMR, 1995.

10 World Health Organization (WHO). Physical Status: The Use and Interpretation of Anthropometry. Report of a WHO Expert Committee. WHO Technical Report Series No. 854. Geneva: WHO, 1995.

11 World Health Organization (WHO). Measuring Change in Nutritional Status. Geneva: WHO, 1983.

12 Gomez F, Galvan R, Frenk S, Cravioto J, Chavez R, Vasquiz J. Mortality in second and third degree malnutrition. Journal of Tropical Pediatrics 1956; 2: 77.

13 Waterlow JC. Classification and definition of protein calorie malnutrition. British Medical Journal 1972; 3: 566-9.

14 Bain BJ. Basic haematological techniques. In: Dacie JV, Lewis SM, eds. Practical Haematology, 8th ed. Edinburgh: ELBS with Churchill Livingstone, 1994; 49-52.

15 World Health Organization (WHO). Nutritional Anaemias. Report of a WHO Expert Committee. WHO Technical Report Series No. 503. Geneva: WHO, 1972.

16 Rao VG, Sugunan AP, Sehgal SC. A profile of demographic and nutritional status of Shompens - the primitive Mongoloid tribe of Great Nicobar. Indian Journal of Community Medicine 1998; 23: 38-41. 
17 World Health Organization (WHO). From Alma Ata to the Year 2000: Reflections at the Midpoint. Geneva: WHO, 1988.

18 Registrar General, India. Sample Registration Bulletin 30(1). New Delhi: Registrar General, India, 1996.

19 Central Bureau of Health Intelligence. Health Information of India. New Delhi: Government of India, 1986.

20 Swaminathan MC, Krishnamurthi D, Iyengar L, Hanumantha Rao D. Health survey of the Onge tribe of Little Andamans. Indian Journal of Medical Research 1971; 59(7): 1136-47.
21 Schroeder DG, Brown KH. Nutritional status as a predicator of child survival: summarizing the association and quantifying its global impact. Bulletin of the World Health Organization 1994; 72(4): 569-79.

22 World Health Organization (WHO). Intestinal Protozoan and Helminthic Infections. Report of a WHO Scientific Group. WHO Technical Report Series No. 666. Geneva: WHO, 1981. 